\title{
Avaliação dos procedimentos simplificados para flambagem elástica de perfis U enrijecidos de paredes finas
}

\author{
Neves, N. S. ${ }^{1 *}$ \\ ${ }^{1}$ COPPE, Programa de Engenharia Civil, Universidade Federal do Rio de Janeiro, RJ, Brasil. \\ *natansian@ufrj.br
}

\begin{abstract}
Resumo
A aplicação de perfis formados a frio em projetos e dimensionamento de estruturas torna-se cada vez mais usual na engenharia. Esses tipos de elementos estruturais apresentam comportamentos físicos suscetiveis aos fenômenos de instabilidade global, local e distorcional. Sendo assim, o presente artigo apresenta um estudo introdutório acerca dos procedimentos simplificados para a estimativa da força axial de flambagem elástica de perfis $U$ enrijecidos de paredes finas. Os testes numéricos são direcionados a partir dos resultados obtidos com o emprego do programa de análise computacional avançada, GBTul, fundamentado na formulação da teoria generalizada de vigas, e com os métodos simplificados descritos na NBR 14762. Em síntese, as discussões são realizadas em torno da análise da curva de assinatura do perfil Ue, das participações dos modos de flambagem associado ao comportamento da estrutura estudada e pelas comparações quantitativas entre as estratégias utilizadas.
\end{abstract}

Palavras-chave: Flambagem elástica, NBR 14762, Perfil formado a frio, Estabilidade.

\section{Introdução}

As estruturas de aço formadas a frio estão sendo bastante utilizadas na construção civil devido ao fácil processo de fabricação e instalação, resultando em elementos estruturais esbeltos, leves e com baixo custo. Todavia, no ponto de visto da análise e dimensionamento estrutural, esses elementos quando submetidos à compressão possibilitam a ocorrência de fenômenos de instabilidades locais, globais e distorcionais, onde devem ser verificadas durante a elaboração dos projetos dessas estruturas [1].

\section{Procedimentos Analíticos}

A força axial de flambagem global elástica por flexão na maior/menor inércia é determinada pela expressão clássica de Euler, conforme dado a seguir:

$$
N_{g}=\frac{\pi^{2} E I}{\left(\kappa \ell_{e}\right)^{2}}
$$

Em que $E$ é o módulo de elasticidade, $I$ é o momento de inércia e o coeficiente $\kappa$ depende do tipo de vinculação utilizada na estrutura.

De acordo com ABNT NBR 14762:2010 [2], a força axial de flambagem elástica local para um elemento submetido à compressão, com base nos princípios da teoria de estabilidade de placas finas [5], é dada a seguir:

$$
N_{l}=k_{l} \frac{\pi^{2} E A}{12\left(1-v^{2}\right)}\left(\frac{t}{b_{w}}\right)^{2}
$$

Onde $A$ é a área e $v$ é o coeficiente de Poisson, igual a 0,3 . Os valores do coeficiente de flambagem local para a seção completa, $k_{l}$, assumem diferentes valores dependendo do tipo de seção. Para uma seção de aço do tipo U 

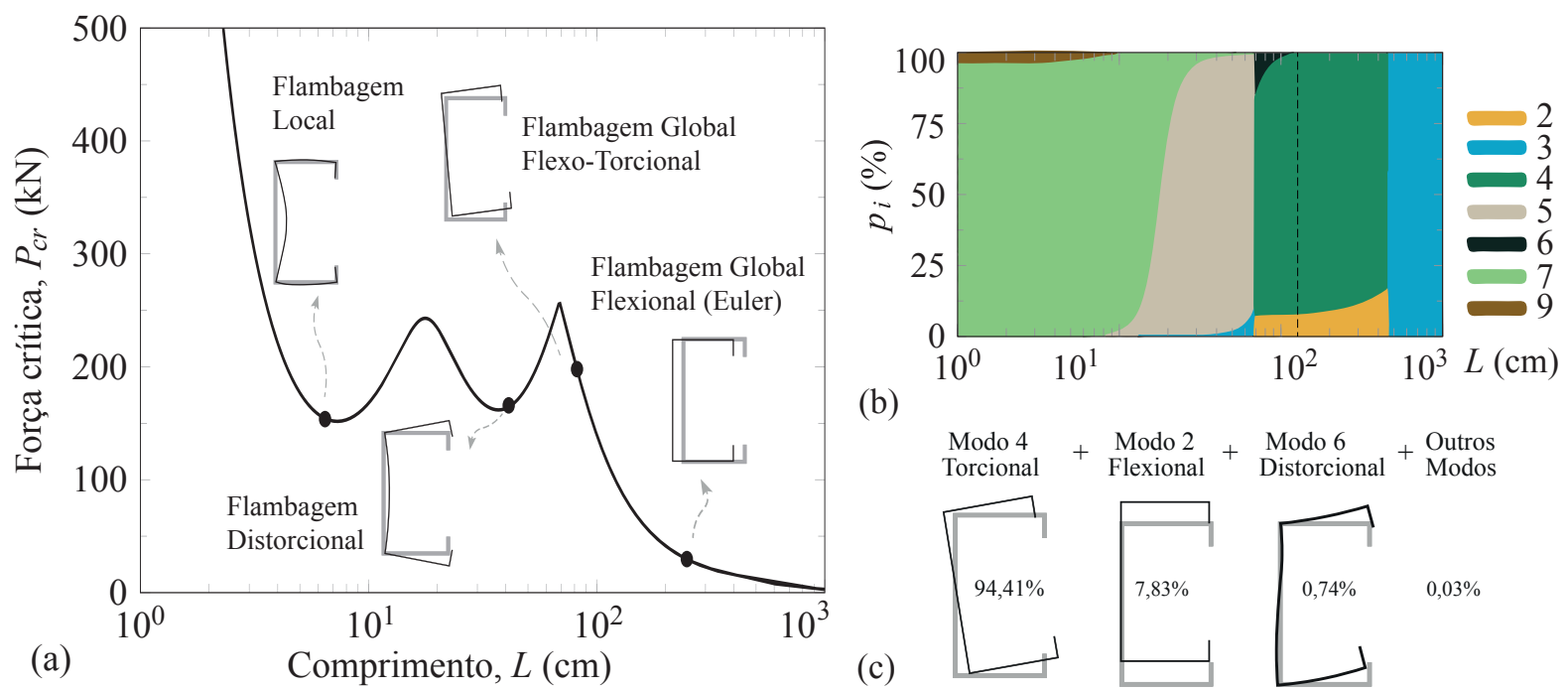

Figura 1: (a) Curva de assinatura do perfil Ue $90 \times 50 \times 12 \times 1,8 \mathrm{~mm}$, (b) interação entre modos de flambagem e (c) participação modal para $L=130 \mathrm{~cm}$.

enrijecido, vale a expressão abaixo:

$$
k_{l}=6,8-5,8 \eta+9,2 \eta^{2}-6,0 \eta^{3}
$$

Onde $b_{f}, b_{w}, b_{s}$ e $D$ são as dimensões nominais dos elementos e $\eta=b_{f} / b_{w}$. A equação (3) é válida para o intervalo de $0,1 \leq \eta \leq 1,0$ e $0,1 \leq D / b_{w} \leq 0,3$.

O fenômeno de flambagem distorcional apresenta uma modelagem robusta, não contendo expressões simples e diretas como os casos de flambagem local e global. Sendo assim, Lau e Hancock [3] desenvolveram um modelo analítico para cálculo da tensão crítica elástica para modo de flambagem distorcional, $\sigma_{\text {dist }}$. A tensão de flambagem elástica por distorção é modelada pela expressão matemática a seguir.

$$
\sigma_{\mathrm{dist}}=\frac{0,5 E}{A_{d}}\left[\alpha_{12}-\sqrt{\left(\alpha_{12}\right)^{2}-4 \alpha_{3}}\right]
$$

Em que $\alpha_{12}=\alpha_{1}+\alpha_{2}$ e as expressões expandidas dos coeficientes da Equação (4) são encontrados no Anexo D: Flambagem por distorção da seção transversal - ABNT NBR 14762:2001 [4]. Outro fator que deve ser observado na análise da flambagem por distorção é o limite de validade da expressão normativa, ou seja, $0,4<b_{f} / b_{w}<2,0$. Para perfis fora dessa faixa é necessário empregar métodos mais precisos.

\section{Resultados e Discussões}

As dimensões e o carregamento de compressão aplicado no perfil formado a frio de seção Ue é mostrado na Figura 2. A primeira análise é determinar a curva de assinatura, conforme Figura 1(a), obtido com programa GBTul [6].
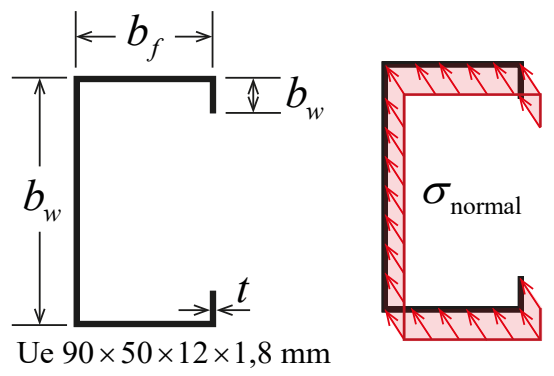

Figura 2: Características da seção de aço do perfil Ue.

Simplificadamente, a curva de assinatura é dividida em três ramos de comportamento relacionados a cada modo flambagem e o comprimento do perfil. Os elementos estruturais curtos são direcionados para a flambagem local, enquanto comprimento intermediários correspondem ao modo distorcional, e por fim, para grandes comprimentos tem-se a ocorrência da flambagem global.

A curva de assinatura de um elemento sujeito à compressão uniforme apresenta características importantes para análise e dimensionamento estrutural. Os pontos mínimos na 


\section{Blucher Proceedings XI Encontro Científico de Física Aplicada}

curva $L-P_{c r}$ correspondentes à flambagem local e distorcional, estabelecendo o valor da força de flambagem elástica local, $N_{\ell}$, e distorcional, $N_{\text {dist }}$, as quais podem ser utilizadas nos procedimentos normativos, como no método da resistência direta (MRD). A força de flambagem global dependem do comprimento do perfil e são obtidas pelas teorias clássicas da estabilidade estrutural.

$\mathrm{Na}$ elaboração e desenvolvimento de projetos, as dimensões, comprimentos e características dos elementos variam com os requisitos solicitados. Neste contexto, na curva de assinatura é possível verificar as contribuições entre os efeitos dos modos em cada faixa de comprimento. Contudo, para facilitar a visualização da participação dos modos de flambagem correspondentes a cada comprimento, apresenta-se na Figura 1(b), um esquema ilustrativo dos percentuais de cada modo.

No programa GBTul, os modos 1-4 são globais, 5-6 são distorcionais e os demais são classificados como locais. Nos comprimentos iniciais, o modo 7 apresenta as maiores participações, enquanto para comprimentos entre o intervalo de $10^{1}$ e $10^{2} \mathrm{~cm}$, tem-se uma predominância do modo 5. Para valores próximos ou maiores de $10^{2} \mathrm{~cm}$, os modos globais apresentam maiores participações.

Quando analisa-se o comprimento proposto de $L=130 \mathrm{~cm}$, linha tracejada na Figura 1(b), pode-se observar que esse comprimento encontra-se no ramo da flambagem global e a maior contribuição é devido ao modo 4. Com base nesses dados, pode-se afirmar que para o referido comprimento adotado, o perfil Ue apresenta um modo crítico de flambagem do tipo flexo-torcional.

Tabela 1: Forças críticas de flambagem elástica global, local e distorcional, em kN.

\begin{tabular}{lccc}
\hline Método & Global & Local & Distorcional \\
\hline NBR 14762 & 88,3 & 153,83 & 163,38 \\
GBTul & 87,5 & 151,98 & 163,12 \\
$\Delta(\%)$ & 0,94 & 1,21 & 0,16 \\
\hline
\end{tabular}

Para facilitar a visualização dos resultados, apresenta-se na Figura 1(c) os modos de flambagem com suas respectivas deformadas e percentuais de contribuição para comprimento testado.
Além disso, conforme apresentado anteriormente, nos métodos normativos descritos na NBR 14762 [2], usualmente é necessário determinar a força de flambagem elástica global, local e distorcional. Esse procedimento pode ser efetuado com as expressões analíticas com base na teoria da estabilidade elástica ou com auxilio de métodos avançados computacionais. Na Tabela 1, mostra-se os valores obtidos para as forças críticas e o erro percentual em comparação com as expressões normativas.

\section{Conclusão}

Esse artigo apresenta um noção introdutório sobre os procedimentos de cálculo para análise de perfis formados a frio. As forças críticas elásticas calculados por meio dos procedimentos simplificados forneceram resultados semelhantes com o programa de referência para o perfil Ue analisado. Além disso, dependendo do comprimento do perfil formado a frio e das características da seção, podem ocorrem comportamentos críticos associados a participação de determinados modos de flambagem. Em modo geral, esse campo de pesquisa são importantes para engenharia, uma vez que as estruturas estão cada vez mais esbeltas, possibilitando a ocorrência de fenômenos de flambagem.

\section{Referências}

[1] JAVARONI, C. Estruturas de aço: dimensionamento de perfis formados a frio. Elsevier, 2015.

[2] ABNT NBR 14762: Dimensionamento de estruturas de aço constituídas por perfis formados. Rio de Janeiro, 2010.

[3] LAU, S. C.; HANCOCK, G. J. Distortional buckling formulas for channel columns. Journal of Structural Engineering, vol. 113, n. 5, pp. 1063?1078, 1987.

[4] ABNT NBR 14762: Dimensionamento de estruturas de aço constituídas por perfis formados a frio - Procedimento. Rio de Janeiro, 2001.

[5] TIMOSHENKO, S. P.; GERE, J. M. Theory of elastic stability. Courier Corporation, 2009.

[6] BEBIANO, R. et al. GBTUL-Buckling and vibration analysis of thin-walled members. Technical University of Lisbon, 2008. 